\title{
Christophe Blanquie, Les masques épistolaires de
} Saint-Simon

\section{Wilma Proglio}

\section{(2) OpenEdition}

\section{Journals}

\section{Edizione digitale}

URL: http://journals.openedition.org/studifrancesi/6304

DOI: $10.4000 /$ studifrancesi.6304

ISSN: 2421-5856

\section{Editore}

Rosenberg \& Sellier

\section{Edizione cartacea}

Data di pubblicazione: 1 novembre 2010

Paginazione: 557

ISSN: 0039-2944

\section{Notizia bibliografica digitale}

Wilma Proglio, «Christophe Blanquie, Les masques épistolaires de Saint-Simon», Studi Francesi [Online], 162 (LIV | III) | 2010, online dal 30 novembre 2015, consultato il 10 janvier 2021. URL: http:// journals.openedition.org/studifrancesi/6304; DOI: https://doi.org/10.4000/studifrancesi.6304

Questo documento è stato generato automaticamente il 10 janvier 2021.

\section{(c) $(7)$}

Studi Francesi è distribuita con Licenza Creative Commons Attribuzione - Non commerciale - Non opere derivate 4.0 Internazionale. 


\title{
Christophe Blanquie, Les masques épistolaires de Saint-Simon
}

\author{
Wilma Proglio
}

\section{NOTIZIA}

CHRISTOPHE BLANQUIE, Les masques épistolaires de Saint-Simon, Paris, Honoré Champion, 2009 («Lumières classiques» 84), pp. 243.

1 Il lavoro di Christophe Blanquie si basa sul corpus della corrispondenza di Louis de Rouvroy, duca di Saint-Simon e pari di Francia, così come è stato riordinato da Yves Coireault e da François Formel nel 1988, al quale si aggiungono alcune lettere rinvenute successivamente. Il nucleo più significativo dell'epistolario di Saint-Simon è rappresentato dalle lettere risalenti al periodo della Reggenza ed in particolare al suo incarico di ambasciatore in Spagna. Nella prima parte di questo libro, intitolata «État de la correspondance», l'autore individua diverse tipologie di missiva, sulla base di criteri principalmente formali. Oltre che sulle lettere tradizionali, egli si sofferma, in particolare, sul biglietto (modalità comunicativa utilizzata frequentemente da SaintSimon, caratterizzata dalla mancanza di espressioni rituali di cortesia), sui placets (comunicazioni pressoché impersonali, spesso prive di data), sulle dépêches (rapporti ufficiali la cui funzione principale è quella dell'informazione) e sulle gazettes, resoconti dettagliati della vita di corte, nei quali trapela un rapporto di speciale confidenza e amicizia con il destinatario. A quest'ultima categoria appartiene in particolare il carteggio con il cardinal Gualterio, risalente al periodo in cui Saint-Simon fu ambasciatore in Spagna. Nella seconda parte del testo, intitolata «Les lettres supposables», Blanquie prende in considerazione alcune lettere che vedono SaintSimon come redattore ma non come firmatario, essendo esse state autografate rispettivamente dal duca d'Orléans, dalla signora di Saint-Simon e dall'abate De la Trappe. Era usanza, da parte dei potenti dell'epoca, far redigere le missive da consiglieri e segretari e in tale pratica è contenuta la testimonianza delle dinamiche di potere, dei rapporti di autorità e anche di clientela del tempo. Blanquie conclude, però, 
affermando che tali epistole non possono essere incluse nel corpus della corrispondenza di Saint-Simon. Nel capitolo "Les lettres des Mémoires», l'autore analizza l'opera principale di Saint-Simon e afferma che le lettere in essa riportate sono state rimaneggiate dallo scrittore e adattate per essere inserite nell'opera. Ciò non deve destare dubbi circa la loro attendibilità, poiché esse sono rimaste inalterate nel loro contenuto, mutando semplicemente nella forma, per conferire loro una modalità espressiva che non avevano nell'originale. La quantità di lettere introdotte nei Mémoires è esigua se rapportata alla consistenza dell'epistolario di Saint-Simon, tuttavia molte missive che non sono riportate direttamente hanno fatto da canovaccio alla ricostruzione dei fatti. Nel quarto capitolo, intitolato «Extraits», Blanquie cerca di ricostruire alcune lettere perdute di Saint-Simon ricorrendo a fonti di seconda mano, come i diari del gesuita Foucquet, che trascrisse alcuni passaggi delle epistole inviategli dal duca. Il capitolo «Des lettres par-dessus les bonnets», ripercorre la vicenda delle lettere collettive inviate dai pari di Francia al reggente Filippo d'Orléans per difendere i privilegi della nobiltà di antico lignaggio. Due di questi testi vengono qui riportati integralmente. Nel sesto capitolo, dal titolo «Les masques de l'anonymat», l'autore si sofferma su alcune lettere anonime attribuite a Saint-Simon. Blanquie sottolinea che lo scopo dell'autore con tali scritti è quello di «créer un état d'esprit, un sentiment qui correspond au sien» (p. 150). Nel capitolo successivo, dal titolo «Les gestes de l'épistolier», vengono analizzate alcune forme ancillari della corrispondenza vera e propria, quali la brutta e la minuta, testimonianze importanti dell'intensa attività epistolare dello scrittore. Blanquie individua inoltre tre livelli di discrezione nella corrispondenza del tempo: quella priva di un codice cifrato, quella codificata dai segretari e quella codificata direttamente dall'autore della missiva. Nel capitolo «Promesses», Blanquie auspica il rinvenimento di ulteriore materiale autografo di Saint-Simon, suggerendo di orientare la ricerca presso gli archivi delle comunità religiose, in considerazione dei numerosi contatti che il duca e pari teneva con questi ambienti. Il capitolo finale, dal titolo "Classement», si configura infine come un esaustivo inventario della corrispondenza attiva di Saint-Simon. 